Revista de Letras

ISSN: 2179-5282

https://periodicos.utfpr.edu.br/rl

\title{
Formação inicial e continuada de professores de línguas. Dimensões e ações na pesquisa e na prática
}

Jozélia Jane Corrente Tanaca

Universidade Estadual de Londrina (UEL)

Londrina, Paraná, Brasil. 
João Telles reúne no livro Formação Inicial e Continuada de Professores de Línguas artigos de pesquisadores do campo da Linguística Aplicada que descrevem projetos de formação, na área de línguas estrangeiras, sob múltiplas abordagens e pontos de vista.

Telles organiza o livro em quatro eixos temáticos que norteiam investigações sobre desenvolvimento de professores, a saber: mediação do desenvolvimento por recursos tecnológicos, papeis da linguagem no desenvolvimento, políticas públicas e ação social, questões de identidade e reflexão sobre a prática docente. Um dos motivos torna a obra relevante é que todos os trabalhos partem de práticas e situações de formação de cunho colaborativo, pautadas na reflexão crítica. As discussões abrangem aspectos amplos que vinculam pressupostos teóricos e metodológicos da perspectiva sócio histórico cultural de ensino aprendizagem e desenvolvimento de professores de língua estrangeira.

Os autores dos trabalhos apresentam bases teórico metodológicas que estruturam suas pesquisas, assim como reflexões quanto à complexidade do campo de formação, o que contribui com leitores envolvidos em pesquisas e práticas de formação inicial e continuada de professores. O objetivo de Telles é colaborar com quem tem interesse em práticas de desenvolvimento profissional que rompem com relações unilaterais de formação.

A primeira parte do livro, cujo eixo temático é o desenvolvimento continuado de professores, mediado por recursos tecnológicos é constituída por dois trabalhos. O primeiro é de Heloisa Collins (PUC/SP) que relata a experiência de integração entre pesquisa, extensão e ensino on line por meio do curso Teacher's links que objetiva o aperfeiçoamento do desempenho em Língua Inglesa e desenvolvimento da capacidade de reflexão crítica sobre a prática pedagógica. A autora traça o histórico, objetivos, estrutura e funcionamento do curso via TELEDUC ${ }^{1}$ e também resultados e avanços com exercícios discursivos, estudos sobre desistências, designs, construção de hipertexto e processos reflexivos em ambiente virtual. A experiência tem concepções de ensino e aprendizagem focadas no planejamento e design de curso via WEB tendo a linguagem como ferramenta de mediação de aprendizagem em tempo e espaço distintos, além de aporte teórico voltado para os conceitos de interação e reflexão crítica. Ao estruturar a base de seu trabalho nestes princípios, Collins apresenta modelo inovador de formação que atende as necessidades de contextos que tem suas práticas de formação restringidas e dificultadas por falta de tempo e espaço.

O segundo trabalho, da primeira parte do livro, é de Rosinda Ramos e Maximina Freire (PUC/SP) que apresentam um projeto de formação de professores multiplicadores para ensino aprendizagem de Inglês Instrumental, no contexto de educação técnico profissionalizante. Ramos e Freire detalham a abordagem instrumental, a formação crítico reflexiva e tecnológica do professor, as etapas do planejamento, implementação do curso, assim como avaliação e resultados obtidos. A abordagem de formação das autoras é interessante pelo aspecto multidisciplinar de aprendizagem, ou seja, engloba o desenvolvimento de nível instrumental e tecnológico atrelado à formação crítica e reflexiva. Fatores de ordem instrumental e técnica não são, de forma geral, associados à reflexão nos contextos de desenvolvimento e aprendizagem.

A parte dois do livro tem como eixo temático a linguagem e o desenvolvimento continuado de professores, trazendo textos de Fernanda Liberali 
e Cecília Magalhães (PUC/SP) e, a seguir, de Deise Dutra e Heliana Mello (UFMG). Magalhães e Liberali discorrem sobre o Projeto de Extensão Ação Cidadã, desenvolvido em escolas públicas de São Paulo, em que a linguagem atua como constituinte da consciência com objetivo de transformação das condições de ensino, pesquisa e formação de professores. A primeira parte do texto das autoras discute os conceitos: colaboração, argumentação, zona de desenvolvimento proximal a partir da TASHC ${ }^{2}$ e aportes teóricos de Vygotsky. A segunda parte descreve a organização do projeto e a parte três discute como a argumentação é praticada e desenvolvida para criar contexto colaborativo a fim de produzir significado compartilhado.

Desenvolvimento crítico e reflexivo por meio de ações colaborativas mediadas pela argumentação é assunto retomado, a seguir, com Dutra e Mello (UFMG). As autoras avaliam como resultados de projetos de pesquisa, de cunho crítico reflexivo, que tem a linguagem como mediadora da reflexão, podem contribuir com a formação continuada de professores. Elas abordam o conceito de emancipação pelo desenvolvimento coletivo da reflexão. As fases do projeto são descritas com foco nos desdobramentos do conjunto de pesquisas desenvolvidas neste estudo. Aspectos alcançados e não alcançados em relação às metas inicialmente estabelecidas são analisados, ficando evidente a importância de organizadores lógico argumentativos, compartilhados em práticas de aprendizagem profissional colaborativa.

Desenvolvimento de professores, políticas públicas e ação social é tema dos capítulos da terceira parte do livro que traz, primeiramente, o trabalho de Angela Lessa e Sueli Fidaldo (PUC/SP) com leitura crítica de políticas de ensino e formação continuada focada na inclusão. Análises de excertos de fala de professores e de condições de ensino e aprendizagem em escolas públicas revelam falta de condições, recursos didáticos e estrutura para atendimento da diversidade. Segundo as autoras, diretrizes educacionais não norteiam claramente sobre procedimentos de ensino com alunos que possuem necessidades especiais, colaboração e criticidade não são termos presentes nos documentos oficiais na educação brasileira. É relevante assinalar, pela leitura do trabalho, que documentos oficiais delegam autonomia aos professores, sem condições de execução de trabalho e abordagem multidisciplinar no contexto da educação inclusiva, especialmente no ensino de língua estrangeira.

Fazendo parte do eixo temático diversidade e heterogeneidade, Aparecida Ferreira (UNIOESTE) inicia o capítulo seis discutindo sobre a questão étnico racial pela análise de histórias de professores de línguas que participaram de um curso de formação, coordenado e implementado por ela. A primeira parte do trabalho de Ferreira trata das políticas e legislação educacional brasileiras e seus desdobramentos em relação à formação de professores, imposições de conteúdo e matriz curricular para o Ensino Médio. A autora aborda na segunda parte do trabalho aspectos metodológicos do projeto, a seguir apresenta resultados quanto a mudanças de visão acerca de racismo e preconceito, necessidade de formação profissional, inclusão, respeito às diferenças no contexto escolar, com a conclusão de que questões étnico raciais devem ser discutidas na formação de professores de línguas.

O capítulo sete traz o trabalho de Kilda Gimenez e Elaine Mateus (UEL) que traçam um percurso histórico de pesquisas sobre formação de professores, atrelado a diferentes sentidos de ser professor e de se formar professores. As 
autoras dedicam uma seção do estudo ao paradigma sócio cultural de pesquisa e formação de professores, cujo foco de abordagem é a interação e o desenvolvimento de atividades por comunidades colaborativas de prática. 0 projeto "Aprendizagem Sem Fronteiras" é apresentado nesta perspectiva, como proposta de ressignificação dos limites da formação inicial e continuada de professores. Seus princípios epistemológicos estão voltados à transformação da ação pelo movimento de expansão e reorganização do sistema de atividades, a partir do aporte da TASHC. O trabalho traz a tona o desafio de lidar com múltiplos e variados sentidos de formação e aprendizagem, rompendo-se com modelos de formação com objetivos previamente estabelecidos.

Com abordagem crítica de formação de professores, Telma Gimenez (UEL) discorre, a seguir, sobre iniciativas de formação de quatro estados brasileiros. A autora analisa propostas de formação dos estados do Rio Grande do Sul, Paraná, Tocantins e Pernambuco, a partir de um roteiro respondido por profissionais envolvidos na formação. O objetivo é compreender as ações, emergência, objetivos, referencial teórico, disseminação, impacto, planos futuros e sustentabilidade no contexto de desenvolvimento e implementação das iniciativas investigadas. $O$ trabalho aponta que os projetos analisados se caracterizam em duas dimensões, a primeira voltada para a relação de provimento de serviços por parte da universidade para com a escola e a segunda dimensão a relação é de quebra de relações hierarquizantes, voltadas à emancipação de professores. Quanto à disseminação e impacto, Gimenez descreve a área como carente de informações. A pesquisa da autora avalia a análise e estabelecimento de uma tipologia de projetos desenvolvidos no país como um tema pertinente e útil, por possibilitar estudo abrangente da diversidade de iniciativas de formação existente no país.

A quarta e última parte do livro, com foco na temática identidade, reflexão e histórias de professores, é composta pelos trabalhos de Solange Castro (UNITAU) e Paula Szundy (UFRJ). Castro trata, inicialmente, pelo relato de suas pesquisas da integração entre ensino, extensão e pesquisa. Seu trabalho está estruturado nas seguintes partes: apresentação do projeto, fundamentação teórica e metodológica pautada no conceito de comunidade de prática, apresentação de ações de formação e discussão de resultados. A participação de estagiários de graduação em atividades de produção de conhecimento partilhado é uma prática relevante no contexto de ações com poder de voz que contribui para a reconstrução do sentido dos fazeres, saberes e reflexões de alunos estagiários do curso de Letras da Universidade de Taubaté.

Szundy encerra o livro com a apresentação do projeto "Sequência Didática para construção da habilidade de leitura em Língua Inglesa: elaboração e aplicação". Seu trabalho traz, inicialmente, uma breve contextualização das ações do projeto, pressupostos que o fundamentam e análise de trechos de relatórios escritos por duas estagiárias participantes. A partir de pressupostos teóricos do círculo de Bakhtin e Vygotsky, os conceitos de zona do desenvolvimento proximal, concepções de ideologia e apreciação valorativa são abordados pela autora na análise crítica e reflexiva de processos de ensino aprendizagem, no contexto de formação de professores de língua estrangeira. O objetivo de Szundy é promover mudanças na maneira de pensar e ver o mundo a fim de que se possa compreender e atuar em contextos permeados de contradições. 
Neste sentido, reitero a relevância da leitura do livro organizado por Telles que retrata a aprendizagem e o desenvolvimento profissional a partir de relações de interação e colaboração entre ensino, pesquisa e extensão com respeito à voz dos professores. Práticas tradicionais de "treinamento e capacitação" de professores, pautadas em aspectos técnicos da profissão, cada vez menos serão capazes de lidar com as complexidades do atual contexto de ensino e formação, como por exemplo: educação inclusiva, questões étnico raciais, inserção e uso crítico de tecnologias no ensino de línguas, falta de tempo para planejamento e pesquisa, precárias condições de trabalho e valorização de professores. Os trabalhos apresentados neste livro são relevantes porque têm compromisso com o desenvolvimento de alunos-professores, professores em serviço e pesquisadores pela capacidade de reflexão crítica, para se alcançar transformações nos contextos de ensino e formação docente na área de línguas estrangeiras.

TELLES, João. Formação inicial e continuada de professores de Línguas. Dimensões e ações na pesquisa e na prática. Campinas, SP: Pontes Editores, 2009.

\section{NOTAS}

1 TELEDUC é um ambiente para a criação, participação e administração de cursos na Web, concebido para formação de professores, baseado na metodologia de formação contextualizada desenvolvida por pesquisadores do NIED (Núcleo de Informática Aplicada à Educação) da Unicamp. http://www.teleduc.org.br/, acesso em 12/08/2013.

2 Teoria da Atividade Sócio Histórico Cultural. 
Recebido: 13 ago 2015

Aprovado: 21 jun. 2016

DOI: $10.3895 /$ rl.v18n22.3152

Como citar: TANACA, J.J.C. Formação inicial e continuada de professores de línguas. Dimensões e ações na pesquisa e na prática. R. Letras, Curitiba, v. 18, n. 22, p. 89-94, jan./jul. 2016. Disponível em: $<$ https://periodicos.utfpr.edu.br/rl>. Acesso em: XXX

Jozélia Jane Corrente Tanaca

Av. Inglaterra, 770, ap. 604, Jardim Igapó, Londrina, PR, CEP 86046000

Direito autoral: Este artigo está licenciado sob os termos da Licença Creative Commons-Atribuição 4.0 Internacional.

(c) (1) 